\title{
Design of High-Speed PM Synchronous Motor-Thermal and Mechanical Analyzes Study for Aerospace Retraction Wheel Motor Application
}

\author{
Pedram Asef and Ramon Bargallo Perpina \\ Department of Electrical Engineering, Polytechnic University of Catalonia-BarcelonaTech, Barcelona, CAT 08036, Spain
}

Received: January 27, 2016 / Accepted: February 17, 2016 / Published: April 30, 2016.

\begin{abstract}
A 3-D modeling of FEA (finite element analysis) design provides for high-speed synchronous with PMs (permanent magnets) applied in aerospace application will be examined under design considerations of $n=12,000 \mathrm{rpm}$, short-duty operation, and etc. for an ARWM (aerospace retraction wheel motor). First, lumped-elements will be fine-tuned following numerical method results is reported steady-state and transient solutions. Besides, the equations of thermal modeling such as $R_{e}, N_{u}, G_{r}$ and $P_{r}$ numbers in order to calculate heat-transfer coefficient of convection on the rotor and stator surfaces in the air-gap have calculated. This section illustrates the temperature distribution of each point in a clear view. By CFD (fluid dynamic analysis) analysis, the fluid dynamics were modeled, pressure and velocity streamlines of cooling-flow have analyzed. An optimization algorithm was derived in order to have optimized number of water-channels as well. Second, calculation of nodal and tangential forces which deal with mechanical stresses of the ARWM have represented. The paper discusses an accurate magnetic-field analysis that addresses equivalent stress distribution in the magnetic core through using the transient FEA to estimate motor characteristics. The whole model shear and normal mechanical stresses and total deformation of the ARWM has been investigated by transient FEA. The end-winding effects were included by the authors.
\end{abstract}

Key words: ARWM, high-speed PM motor, redundant winding, equivalent stress distribution, lumped-elements.

$\begin{array}{ll}\text { Nomenclature } \\ T & \text { Electrical cycle } \\ \rho & \text { Fluid density } \\ h & \text { Heat transfer coefficient }\left(\mathrm{W} / \mathrm{m}^{2} /{ }^{\circ} \mathrm{C}\right) \\ \sigma & \text { Conductivity } \\ \beta & \text { Coefficient of cubical expansion, }\left(1 / 273+T_{f l u i d}\right) \\ g & \left(1 /{ }^{\circ} \mathrm{C}\right) \\ L & \text { Gravitational force of attraction }\left(\mathrm{m} / \mathrm{s}^{2}\right) \\ V_{s} & \text { Characteristic length of the surface }(\mathrm{m}) \\ B_{p t} & \text { Supply voltage to the controller } \\ B_{m t} & \text { Peak tooth flux-density } \\ B_{c s} & \text { Peak flux density in stator tooth on open-circuit } \\ \mu & \text { Flux density in the stator core } \\ D_{m a g} & \text { Fluid dynamic viscosity }(\mathrm{kg} /(\mathrm{s} \cdot \mathrm{m})) \\ D_{s h} & \text { Density of magnet material } \\ D_{s e} & \text { Shaft diameter } \\ D_{r} & \text { Stator outer diameter }\end{array}$

Corresponding author: Pedram Asef, $\mathrm{PhD}$, research fields: electrical machinery and its drives.

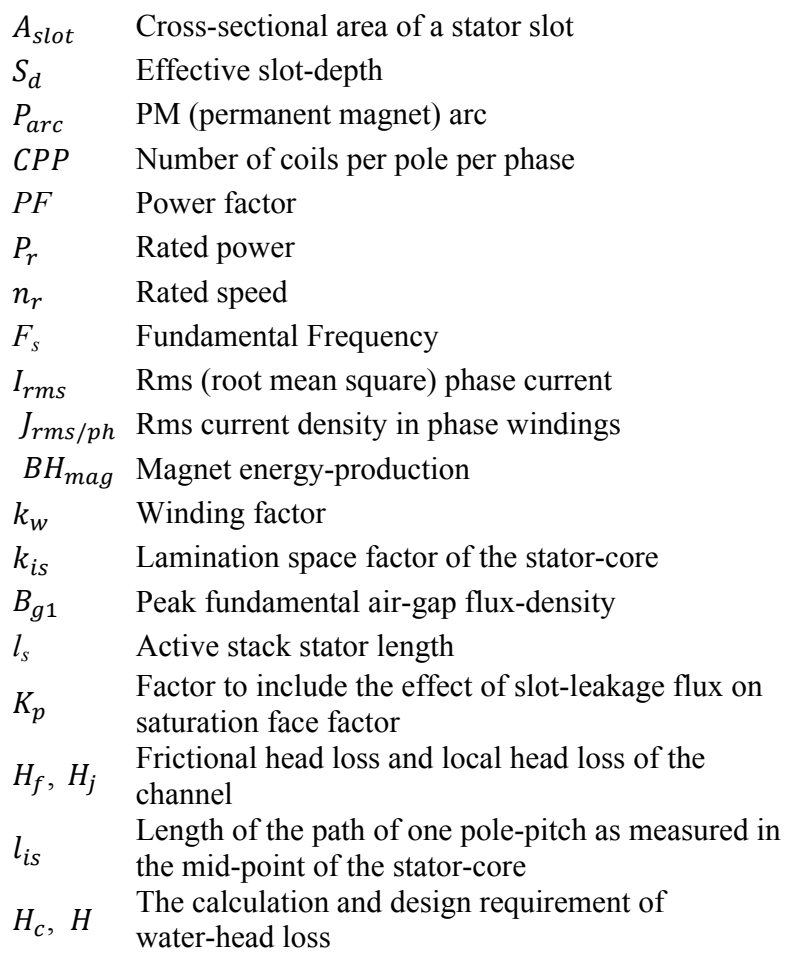



Study for Aerospace Retraction Wheel Motor Application

$m \quad$ Stator number of phases

$N \quad$ Number of turns per phase

$p \quad$ Number of pole pairs

$Q_{s} \quad$ Total number of the stator slots

$T_{p h} \quad$ Turns in series per phase

$\delta_{g} \quad$ Air-gap length

$\delta \quad$ Torque angle

$\kappa \quad$ Fluid thermal conductivity

$C_{p} \quad$ Specific heat $\left(\mathrm{kJ} / \mathrm{kg} /{ }^{\circ} \mathrm{C}\right)$

$\Delta T \quad$ Delta temperature of surface-fluid $\left({ }^{\circ} \mathrm{C}\right)$

$R_{e}, N_{u}$ Reynolds and Nusselt numbers

$G_{r}, P_{r} \quad$ Grashof and Prandtl numbers

$L F V \quad$ Local fluid velocity

$v \quad$ Axial fluid velocity

$\% \eta \quad$ Percentage of the efficiency

\section{Introduction}

In the application area of aerospace, highly engineered with smallest motor and sensor types are at harsh environment. High performance and precision which provided through embedded 3-D FEA (finite element analysis). Whereas the following clues have derived in the ARWMs (aerospace retraction wheel motors) design such as short-duty, low cogging, high efficiency at peak torque, banded rotor/large air-gap, redundant windings that occurs resistant to fault propagation, react time almost $\leq 10 \mathrm{~s}$, must withstand by two consecutive extend/retract cycles. Through below schematic, better understanding of the application represented by Fig. 1 [1-3].

In this research, baseline of the motor topography will be discussed by authors. Besides, shrinking motor dimensions until desired temperature rise has reached. In case of such a highly demanding application, HSPMSM (high-speed surface-mounted pm synchronous motor) topology proposed with proper results in terms of electromagnetic analysis and losses calculation by the authors.

For the PMs (permanent magnets) (Nd-Fe-Br (reversible)) fixed on the rotor core which is surface-mounted magnets retained by a carbon-fiber bandage, because improved tensile modulus and adhesion properties over T700S type, where applications of this never twisted fiber include aircraft/airplane and high performance sporting goods, where demanding conditions require superior composite properties.

As the Fig. 2 shows the construction, an axial water-jacket housing without end-cap cooling has been derived.

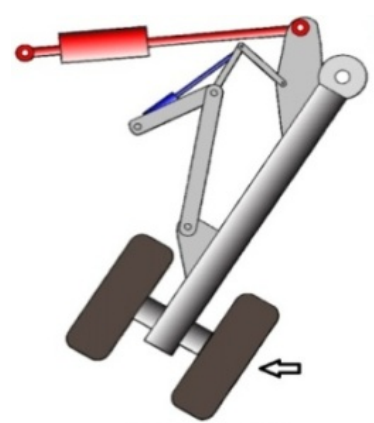

Operation time $(t>0)$

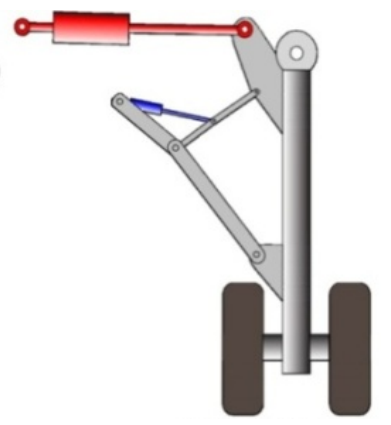

Standby time $(t=0)$
Fig. 1 Schematic of the studied ARWM for airplane application.

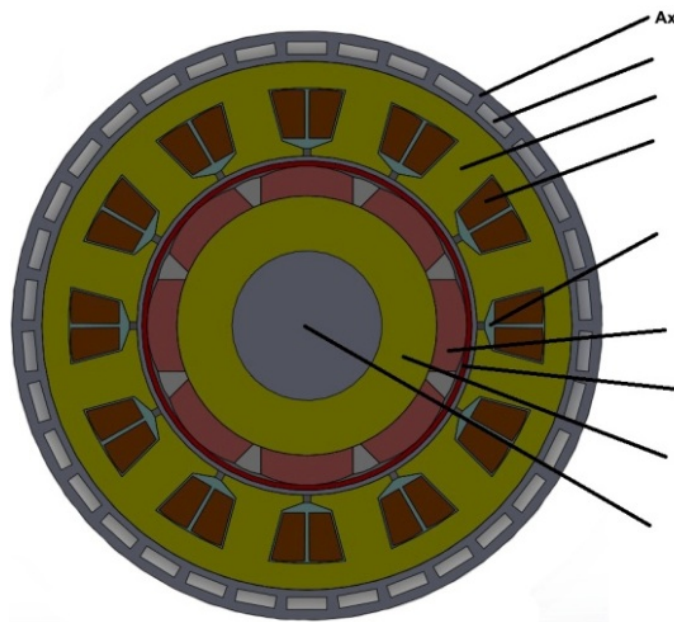

(a)

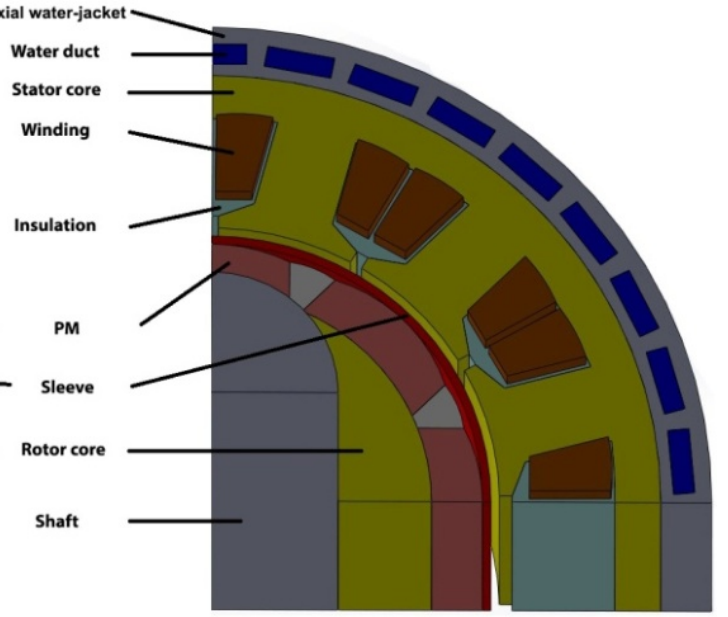

(b)

Fig. 2 Designed prototype of the ARWM in (a) 2-D model and (b) 3-D with 1/4 of whole model and 1/2 length. 


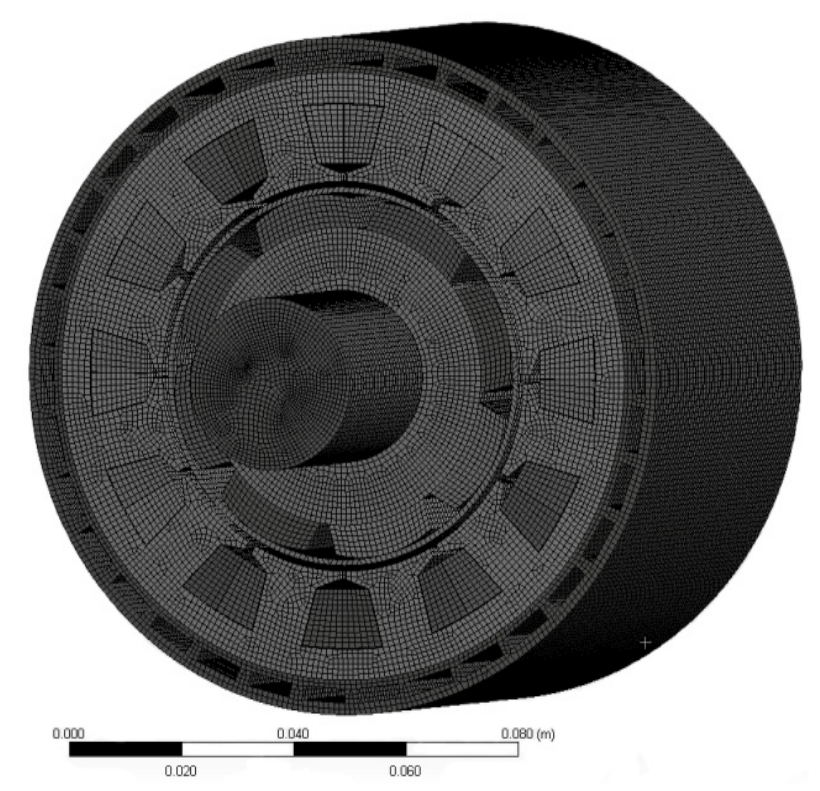

Fig. 3 Generated mesh for the whole model.

In order to have the highest accuracy for the simulation, the maximum accessible number of elements of a competent mesh has noticed by 991,253 elements and 4,561,205 of nodes which can be seen by Fig. 3.

The electromagnetic-field analysis capability of this model has been reported by Ref. [4]. Besides, all design data of the model has been given in appendix.

\section{Thermal Analysis through Embedded 3-D FEA}

In terms of the thermodynamic, for convection, the typical forms of the convection correlation [5] can be define as:

$$
\begin{gathered}
N_{u}=a\left(G_{r} \cdot P_{r}\right)^{b} \quad \text { (natural) } \\
N_{u}=a\left(R_{e}\right)^{b} \cdot\left(P_{r}\right)^{C} \text { (forced) }
\end{gathered}
$$

where, all constants have given in the correlation. Besides, $R_{e}$ (to recognize laminar/ or turbulent flow in the forced convection system), $N_{u}, G_{r}$ and $P_{r}$ can be defined as below [5]:

$$
\begin{gathered}
R_{e}=\rho \cdot v \cdot L / \mu \\
N_{u}=h \cdot L / k \\
G_{r}=\beta \cdot g(\Delta T) \cdot \rho^{2} \cdot L^{3} / \mu^{2} \\
P_{r}=C_{p} \cdot \mu / k
\end{gathered}
$$

In the water-jacket, number of water-channels is $d_{n}=34$, with $85 \times 10^{-5} \mathrm{~m}^{3} / \mathrm{s}$ of fluid volume flow rate, $\kappa=0.125 \mathrm{~W} /\left(\mathrm{m} \cdot{ }^{\circ} \mathrm{C}\right), \rho_{w}=1,000 \mathrm{~kg} / \mathrm{m}^{3}, C_{p}=$ $1.88 \mathrm{~kJ} /\left(\mathrm{kg} \cdot{ }^{\circ} \mathrm{C}\right), R_{e}=1.55 \mathrm{E} 04$ and $L F V=53.37 \mathrm{~m} / \mathrm{s}$ have derived in order to abound the temperature along minimizing losses. Where for water-jacket channel is required to calculate $N_{u}$ (while rectangular channel has been chosen) by below expression:

$$
\begin{gathered}
N_{u}=7.49-17.02\left(\frac{H}{W}\right)+22.43\left(\frac{H}{W}\right)^{2}- \\
9.94\left(\frac{H}{W}\right)^{3}+\frac{\left[0.065\left(\frac{D}{L}\right) R_{e} \cdot P_{r}\right]}{\left[1+0.04\left(\left(\frac{D}{L}\right) R_{e} \cdot P_{r}\right)^{\frac{2}{3}}\right]} \text { (for laminar-flow) }
\end{gathered}
$$

where, $\left(\frac{H}{W}\right)$ is the channel height/width ratio and $\left(\frac{D}{L}\right)$ is the channel hydraulic diameter times gap for concentric cylinders, and times channel cross-sectional area divided by channel-perimeter in rectangular channels design $[5,6]$.

In turbulent-flow case, the flow can be assumed to be completely laminar when $R_{e}<2,300$ in rectangular channels. The flow is assumed to be completely turbulent when $3,000<R_{e}<10,000$.

$$
N_{u}=\frac{\left(\frac{f}{8}\right) \cdot\left(R_{e}-1,000\right) \cdot P_{r}}{1+12.7 \cdot\left(\frac{f}{8}\right) \cdot(0.5) \cdot\left(P_{r}^{\frac{2}{3}}-1\right)}(\text { for turbulent-flow) }(8)
$$

where, $f$ known as friction factor and can be assumed for a smooth channel-wall [6] as:

$$
f=\left(0.790 \times \operatorname{Ln}\left(R_{e}\right)-1.64\right)^{-2}
$$

In order to calculate heat transfer base on $R_{e}$, Taylor number $\left(T_{a}\right)$ can be accounted for recognizing the form of flow (laminar, vortex or turbulent).

$$
T_{a}=R_{e}\left(\frac{\delta_{g}}{R_{r}}\right)^{0.5}
$$

where, $R_{e}$ should be calculate by $\delta_{g}$ (not $L$ ) and $R_{r}$ is the rotor radius.

Eventually, the mixed heat transfer due to the combination of natural and forced convection can be estimated by using the below formulation $[5,6]$.

$$
h_{\text {mixed }}^{3}=h_{\text {natural }}^{3}+h_{\text {forced }}^{3}
$$

Sensitivity analysis can be used for quickly identify the main parameters that influence the thermal 
performance [7].

From Fig. 4, the sensitivity of the $R_{e}$ (effective and air-gap rotational) based on the shaft speed variation has be reported. Fig. 5 represented the sensitivity of the $N_{u}$ to the shaft speed variation as well. Where four different calculation methods such as Taylor, Gazley, Kosterin Finative and Tachibana Fukui methods have been considered.

By Fig. 6, the sensitivity of the temperature rise in different part of the designed motor based on the shaft speed variation.

Steady-state lumped circuit model has been showed a perfect presentation of heat-transfer analysis that is the thermal counterpart to electrical network analysis with the following equivalences: temperature to voltage, power to current and thermal resistance to electrical resistance in form of a schematic in Fig. 7. Generally, this circuit is made of thermal resistances and heat sources which are connected to a number of nodes. The power and temperature of each section and node have been represented through this thermal circuit as well.

While different colors have defined different sections where water-jacket housing, end-cap, stator yoke plus tooth, winding, PM, rotor core, and shaft are in blue, orange, red, yellow, green, turquoise and grey, respectively.

As there is always a trade-off between accuracy and calculation speed, steady-state lumped circuit model can indicates a good global accuracy which means not as much localized detail as CFD (fluid dynamic analysis)/FEA. However, that is much less time consumable and costly.

In the following, well-known transient thermal analysis will show a better understanding of the temperature distribution on the ARWM through Fig. 8.

From Fig. 8, the transient temperature distribution of a quarter of the whole model with half length was presented which matched the steady-state results as well. Temperature rise of the model by time is during TPT (transient period time) to the peak operation point has clearly been represented the right trend of the operation. In Fig. 9, total heat flux distribution of the model in three main obvious changes during the TPT was showed. Also, that is palpable which the most heat fluxes have been occurred around the water-jacket channels because there is the only cooling flow (axially-move) in the ARWM.

The pressure distribution and velocity streamlines of the fluid in the channels became as perfect as that is reported through Fig. 10, where the velocity of water reported in average $5 \mathrm{E}+001(\mathrm{~m} / \mathrm{s})$. In CFD analysis, following algorithm (Fig. 11) has been taken into account in order to have optimized number of the water-jacket channels.

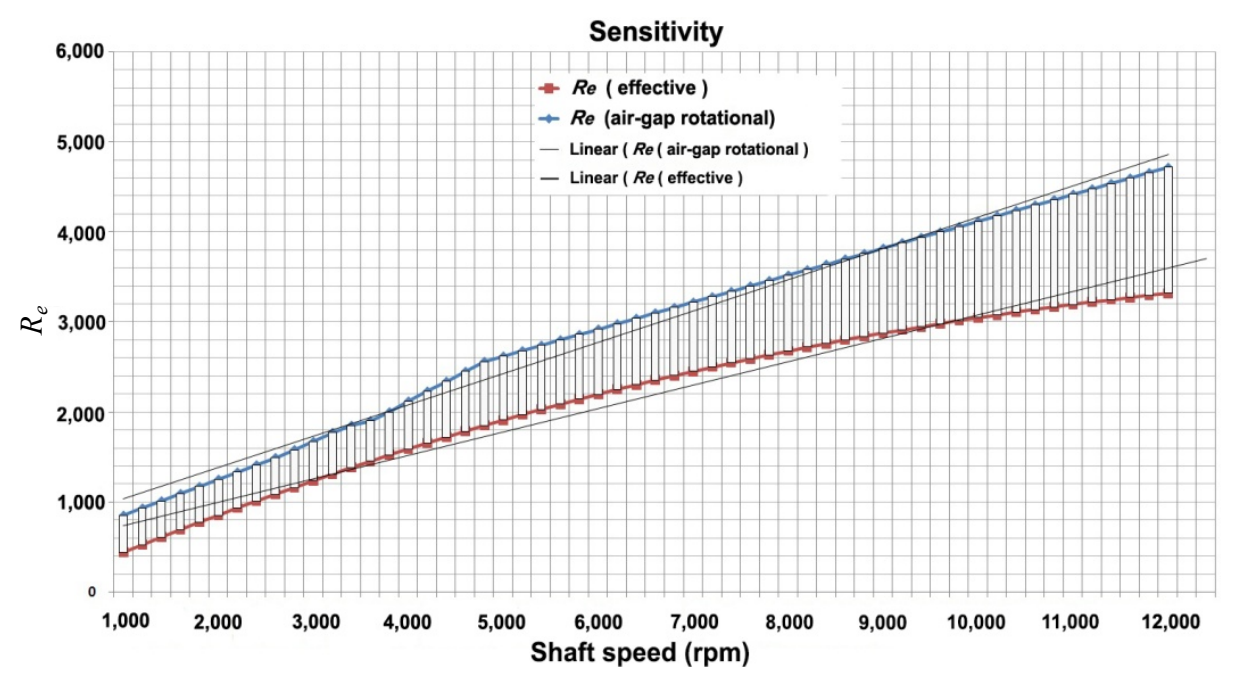

Fig. 4 Comparison between the sensitivity of the effective and air-gap rotational $R_{e}$ based on the shaft speed variation. 

Study for Aerospace Retraction Wheel Motor Application

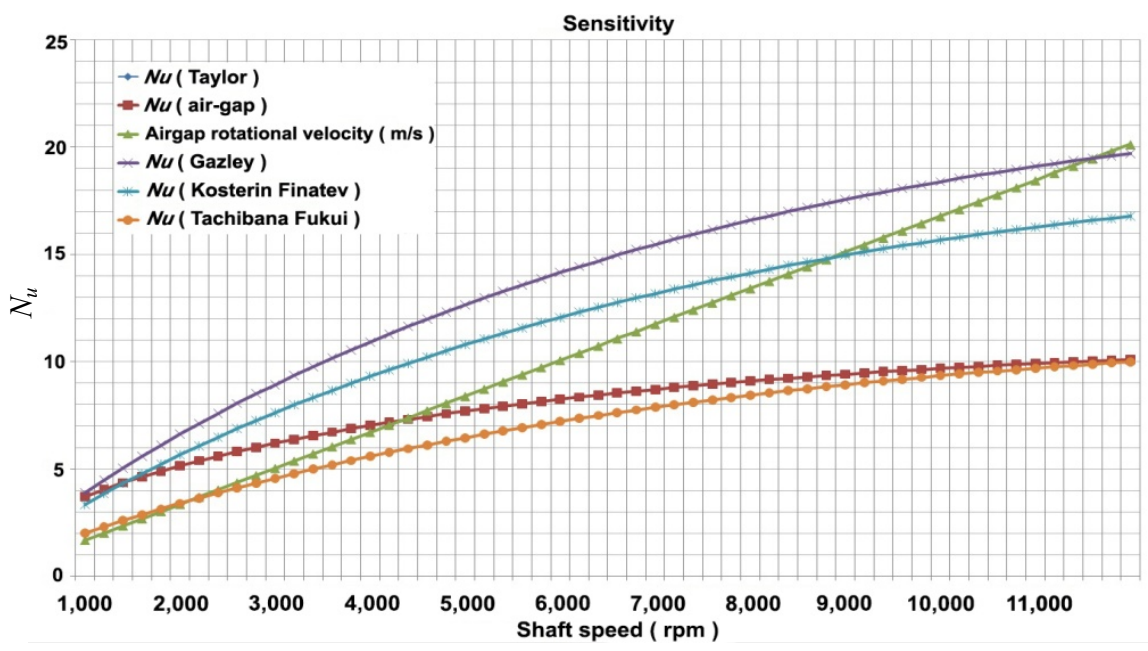

Fig. 5 Comparison among different calculation methods for the sensitivity of the $N_{u}$ based on the shaft speed variation.

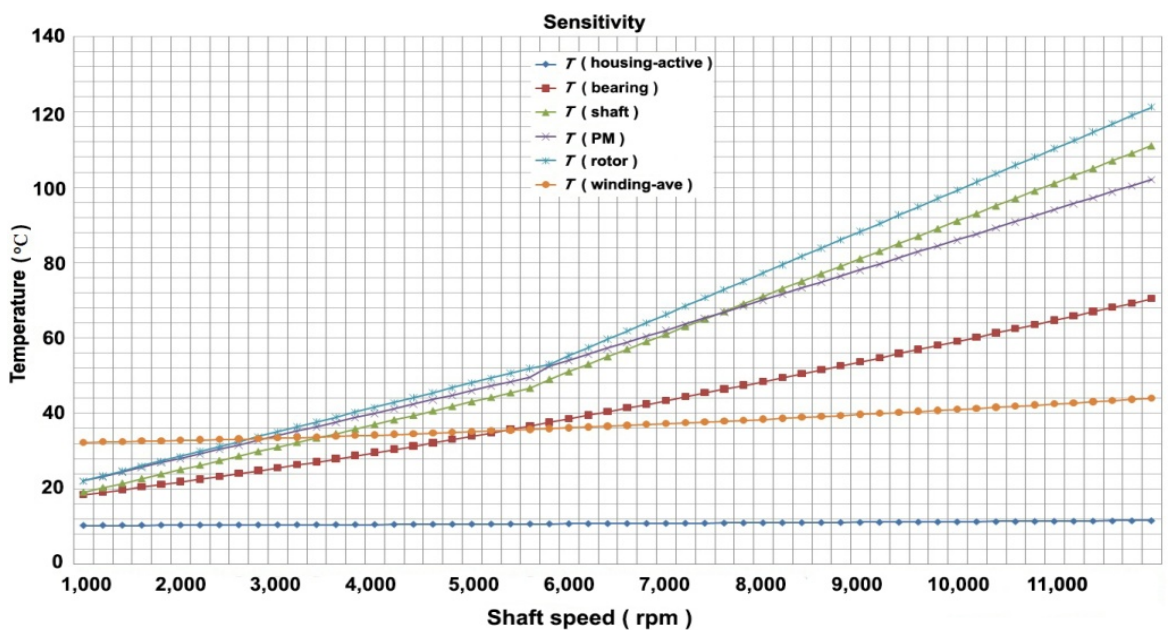

Fig. 6 Comparison among different calculation methods for the sensitivity of the $R_{e}$ based on the shaft speed variation.

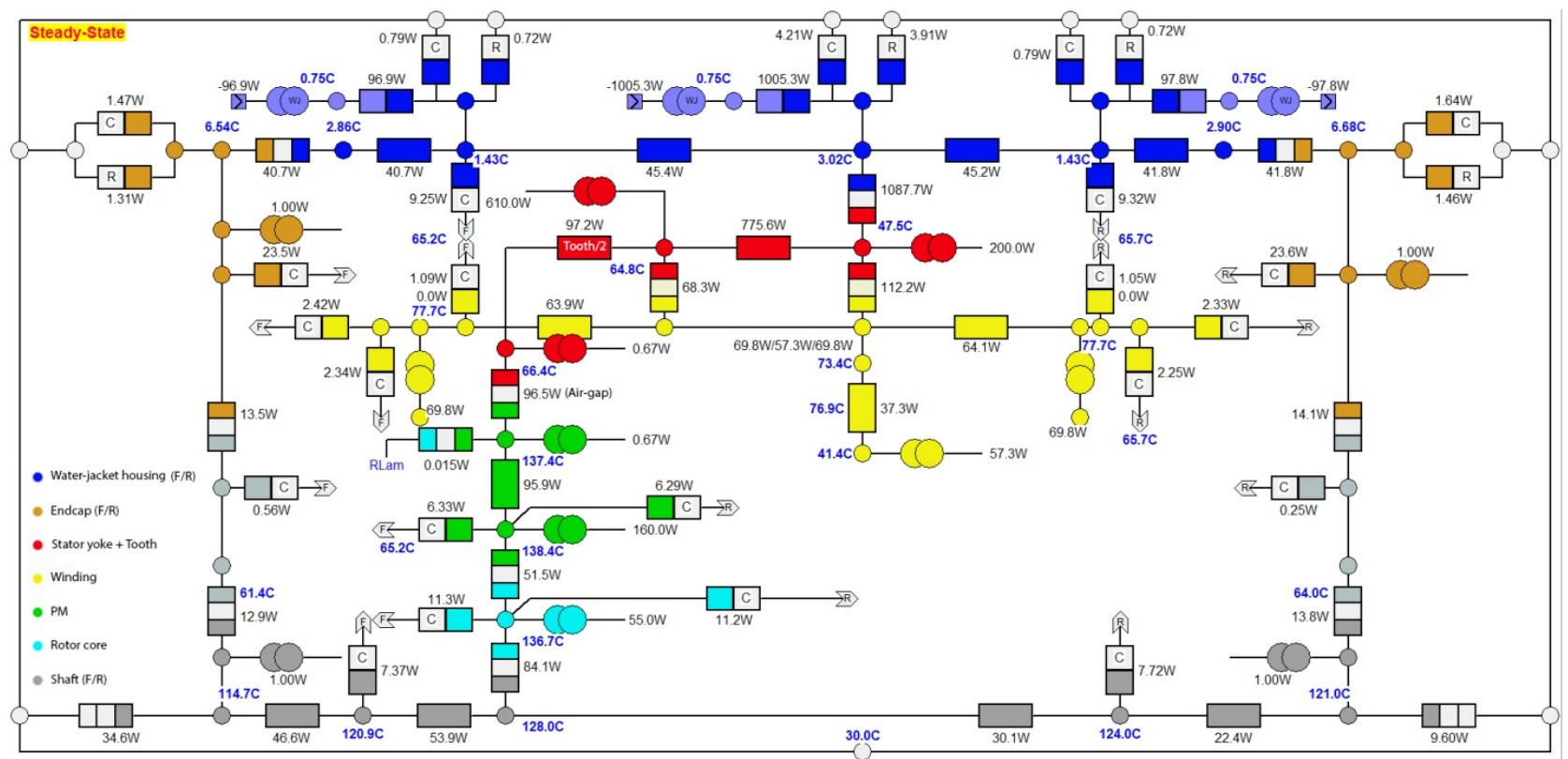

Fig. 7 Steady-state lumped circuit model of the ARWM. 
Study for Aerospace Retraction Wheel Motor Application

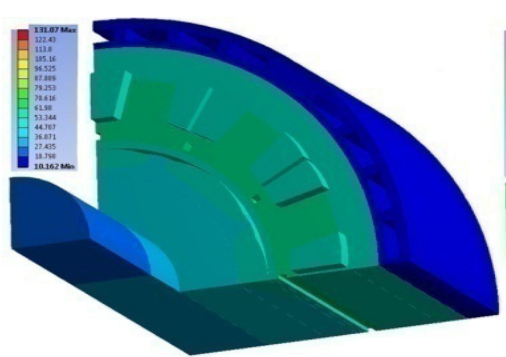

(a)

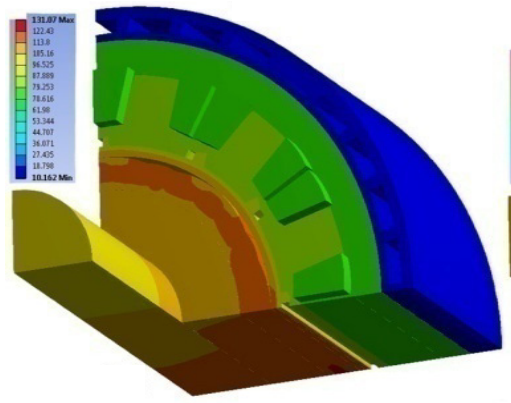

(c)

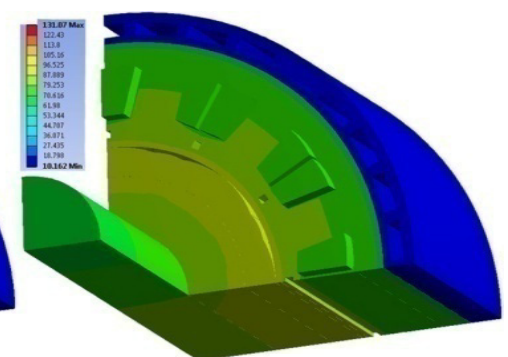

(b)

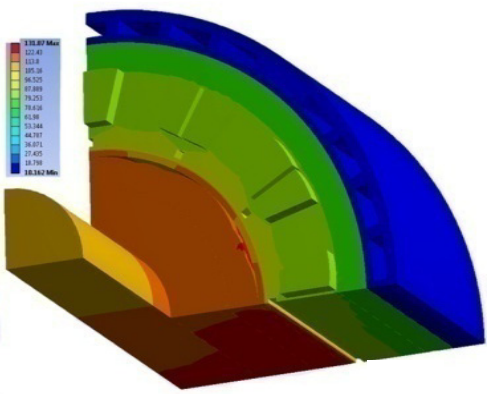

(d)

Fig. 8 Transient temperature distribution of the ARWM: (a)@1/7 of the whole transient period time TPT, (b)@1/3 of whole TPT, (c)@1/5 of the whole TPM, (d) @ peak-point of the whole TPT.

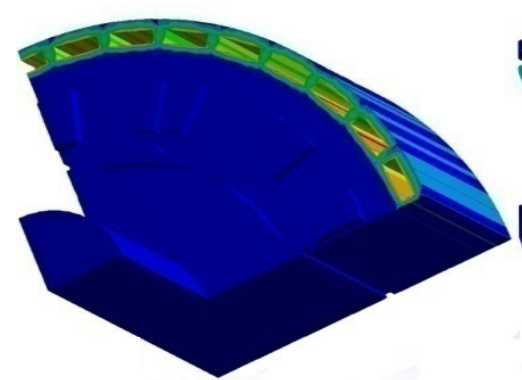

(a)

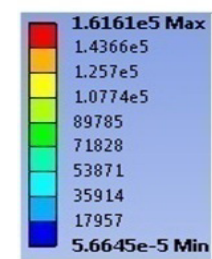

$(a, b)$

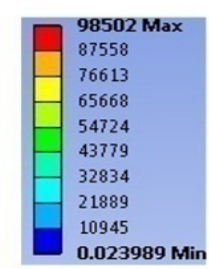

(c)

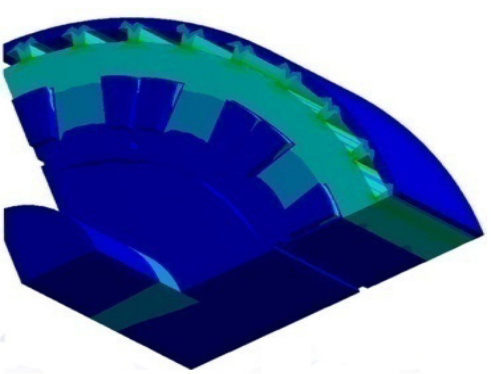

(b)

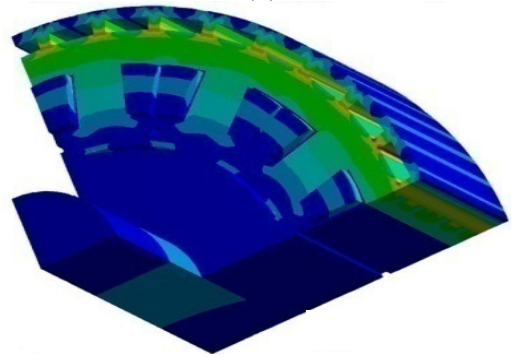

(c)

Fig. 9 Transient total heat flux distribution of the ARWM: (a) @ Os of the whole TPT, (b) @ 1/2 of the whole TPT, (c) @ peak-point of the whole TPT.

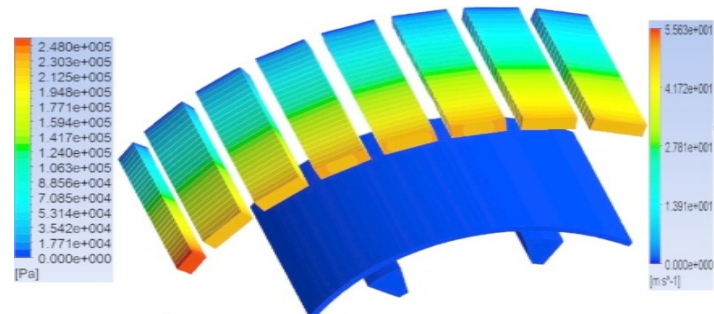

(a)

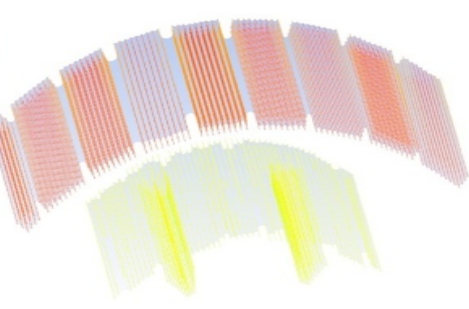

(b)

Fig. 10 CFD of the ARWM: (a) pressure distribution of the model in (Pa), (b) velocity streamlines of the fluid in ( $\mathrm{m} / \mathrm{s})$. 


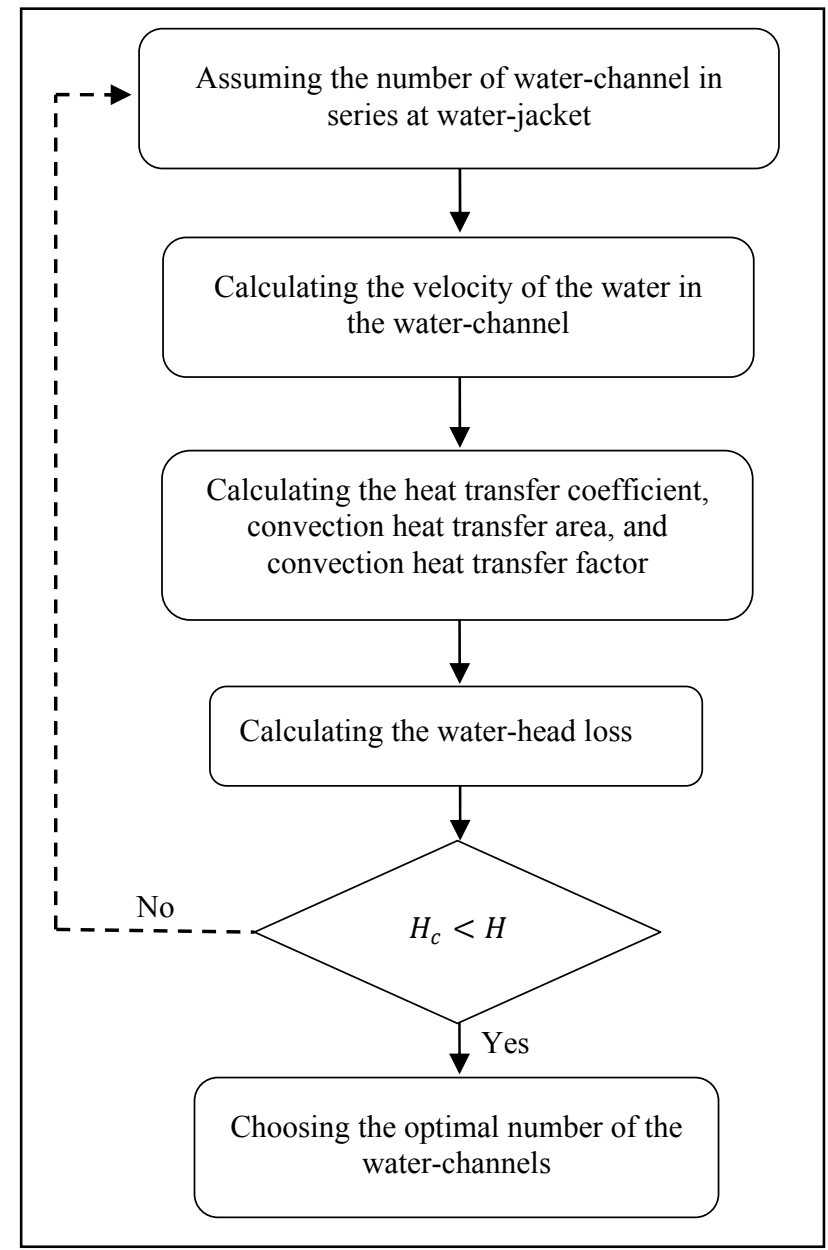

Fig. 11 The optimization design scheme of the water-jacket.

In where, the water-head loss $H_{c}$ was calculated through $H_{f}$ and $H_{j}$ as following:

$$
\begin{aligned}
& H_{f}=\xi_{f} \cdot \frac{l}{d}\left(\frac{V^{2}}{2 g}\right) \\
& H_{j}=\xi_{l} \cdot\left(\frac{V^{2}}{2 g}\right)
\end{aligned}
$$

And then,

$$
H_{c}=\sum H_{f}+\sum H_{j} \leq H
$$

where, $\xi_{f}, \xi_{l}, V, d$ and $g$ are frictional head loss coefficient, local head loss coefficient, the velocity of cooling water, the hydraulic diameter of water channel and Gravitational acceleration, respectively [3].

\section{Mechanical Stress Analysis by Embedded 3-D FEA}

As accuracy must be performed through well done design in such this application, in this study, the influence of the mechanical stress and deformation analyzes on the model have been accounted through transient solution. Because in the high-speed applications, often the mechanical stress and deformation problems remain as critical challenges specially on torque and iron losses. In this study, following expressions are carried out to determine these two problems.

$$
\begin{aligned}
& {[M]\left\{\ddot{u}_{n+1}\right\}+[C]\left\{\dot{u}_{n+1}\right\}+[K]\left\{u_{n+1}\right\}=\left\{F^{a}\right\}} \\
& \left\{u_{n+1}\right\}=\left\{\dot{u}_{n}\right\}+\left[(1-\delta)\left\{\ddot{u}_{n}\right\}+\delta\left\{\ddot{u}_{n+1}\right\}\right] \Delta t
\end{aligned}
$$

Where, $[M],[C],[K], \ddot{u}, \dot{u}, u$ and $\left\{F^{a}\right\}$ are structural mass matrix, structural damping matrix, structural stiffness matrix, nodal acceleration vector, nodal velocity vector, nodal displacement vector and applied load vector, respectively. While this approach accounts finite difference expansions at the time interval $(\Delta t)$, therefore, $\left\{u_{n+1}\right\}$ is carried out into the main expression Eq. (15). In addition, $\delta$ is new-mark integration parameter [8].

This study is based on below material properties (Table 1).

Besides, in order to calculate mechanical problems, that is required to firstly calculate nodal and tangential forces. In this design prototype, nodal force is 2,668 (N), and tangential force is $570.3(\mathrm{~N})$.

Table 1 Material properties of the designed ARWM.

\begin{tabular}{lllllll}
\hline Quantity & Unit & Stator/rotor cores & PM & Winding & Sleeve & Slot insulation \\
\hline Density & $\mathrm{kg} / \mathrm{m}^{3}$ & 7,650 & 7,500 & 8,960 & 1.8 & 2,000 \\
Young's modulus & $\mathrm{pa}$ & $2.1 \mathrm{E}+11$ & $1.4 \mathrm{E}+11$ & $2 \mathrm{E}+11$ & $1.2 \mathrm{E}+11$ & $8 \mathrm{E}+10$ \\
Poisson's ratio & - & 0.27 & 0.24 & 0.3 & 0.3 & 0.3 \\
Bulk modulus & $\mathrm{pa}$ & $1.5 \mathrm{E}+10$ & $8.9 \mathrm{E}+10$ & $1.6 \mathrm{E}+11$ & $1 \mathrm{E}+11$ & $6.6 \mathrm{E}+10$ \\
Shear modulus & $\mathrm{pa}$ & $8.3 \mathrm{E}+10$ & $5.6 \mathrm{E}+10$ & $7.7 \mathrm{E}+10$ & $4.6 \mathrm{E}+10$ & $3 \mathrm{E}+10$ \\
\hline
\end{tabular}


In Fig. 12, mechanical stress through transient solution has been indicated where maximum stress has been addressed with $610(\mathrm{MPa})$ which happened at 135 (s). As Fig. 13 presents the averaged mechanical stress, maximum stresses have been appeared on the yoke and tooth tips of the stator.

In this section, mechanical transient analysis has performed for both prototype and the final design model, by commercial software "ANSYS" to calculate centrifugal force mechanical stress, and deformation on the ARWM.

In the following, the second most influence problem in terms of mechanical analysis which called deformation (um). In this application, that should be well know as a critical problem by designers which as this type of application runs only for short-duty operations, from startup to a few seconds, the value of deformation should be kept almost zero. Fig. 14 illustrated variation of maximum deformation (on-load) of the designed ARWM.

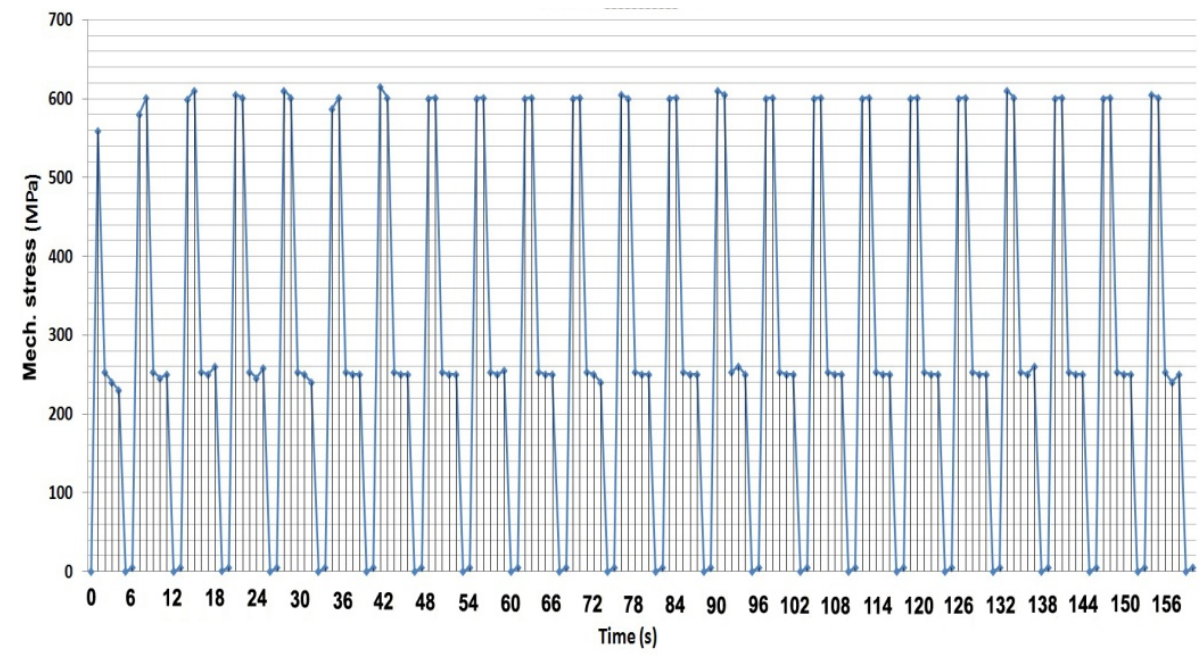

Fig. 12 Result of transient mechanical stress analysis.

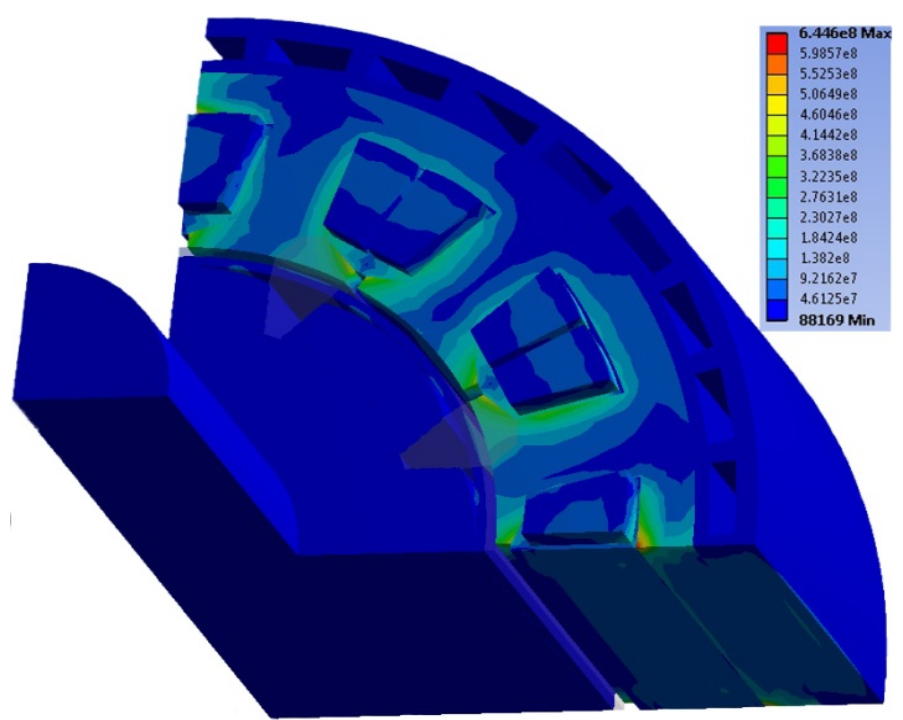

Fig. 13 Transient averaged mechanical stress (on-load) analysis in the ARWM. 


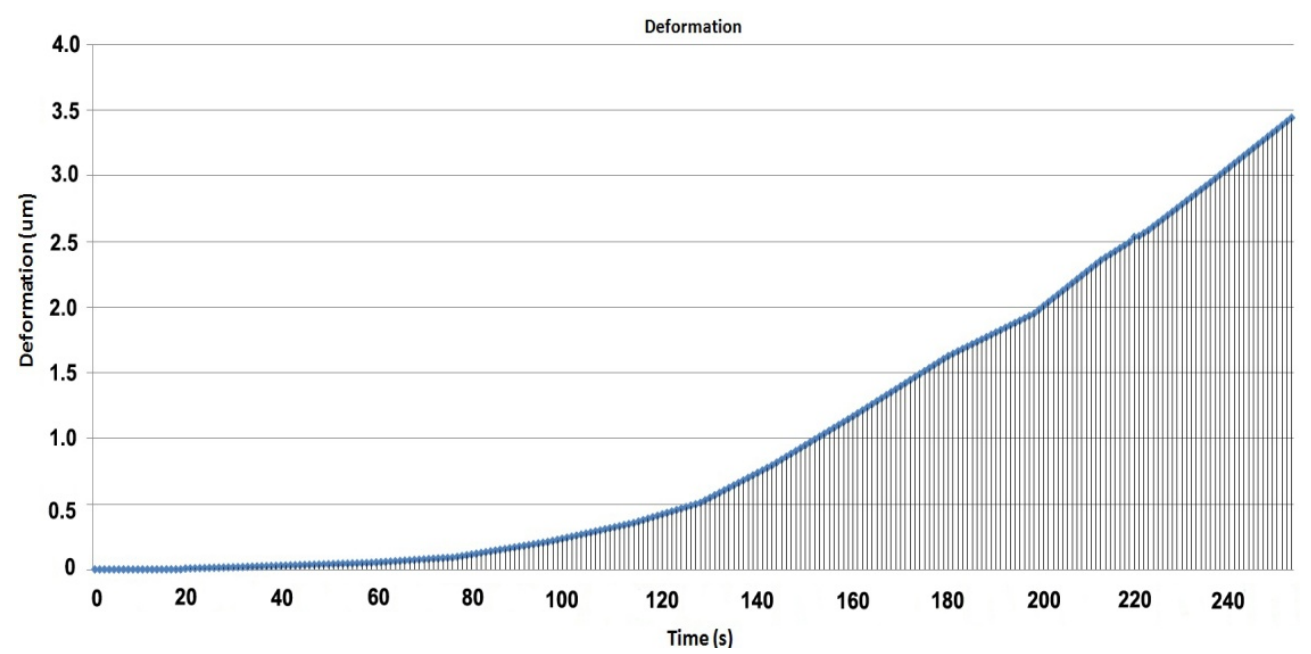

Fig. 14 Transient deformation result of the ARWM.

\section{Conclusions}

In this research, several purposes have been studied through the most accurate forms of design which call 3-D steady-state and transient solutions. As the electromagnetic-field analysis capability was addressed, no discussion relied on this paper correspond to that and its losses. This paper only focused on thermal and mechanical analyzes and discussion of its result.

First, in the introduction section, we performed the design boundaries by mentioning to the critical design factors on this type of application, and the generated mesh in extremely perfect form was carried out in 3-D.

Second, in the thermal analysis section, the paper has focused strongly on convection correlation calculation with comparison through different methods in order to gain the most accurate value of heat transfer of the ARWM. After that, steady-state lumped (thermal) circuit was represented. In the following, the attention was focused on transient solution with keen interest on temperature distribution, total heat flux distribution, and fluid dynamic (pressure distribution and velocity streamlines of the fluid). As results showed, the most temperature appeared on the dynamic part (rotor core, PMs and shaft) of the model besides, an optimization algorithm was studied in order to achieve optimized number of water-channel in the ARWM model.

Third, in the mechanical analysis section, the study focused on the transient stress and deformation on the model. In where, the most of the stresses occurred in the stator yoke and tooth tips according to the averaged stress report.

The results of this research were performed by several specific commercial software such as ANSYS, JMAG, Motor-CAD, MATLAB and SPEED. The design model of geometry and FEA design data have been given in the appendix.

\section{Appendix}

In this section, the ARWM and FEA data have indicated in Tables 2 and 3 [4], as following.

In addition, the results of losses calculation has presented through Table 4 [4].

Table 2 Design of The ARWM geometry.

\begin{tabular}{lll}
\hline Variable & \multicolumn{2}{l}{ Linear current density fixed } \\
\hline$l_{s}$ & 80 & $\mathrm{~mm}$ \\
$D_{s h}$ & 30 & $\mathrm{~mm}$ \\
$D_{r}$ & 64 & $\mathrm{~mm}$ \\
$D_{s e}$ & 106 & $\mathrm{~mm}$ \\
$A_{\text {slot }}$ & 130 & $\mathrm{~mm}^{2}$ \\
$\delta_{g}$ & 2 & $\mathrm{~mm}$ \\
$P_{\text {arc }}$ & 130 & $\mathrm{~mm}$ \\
$S_{d}$ & 13 & $\mathrm{~mm}$ \\
$Q_{s}$ & 12 & \\
Slots/pole & 1.5 & \\
$P$ & 4 & \\
$m$ & 3 & $\mathrm{~mm}$ \\
$W_{p h-s}$ & 3 & \\
\hline
\end{tabular}


Table 3 FEA design data.

\begin{tabular}{lll}
\hline Variable & Value & Unit \\
\hline$V_{s}$ & 690 & $\mathrm{~V}$ \\
$B_{r} @ 20^{\circ}$ & 1.3 & $\mathrm{~T}$ \\
$H_{c}$ & 1,592 & $\mathrm{kA} / \mathrm{m}$ \\
$D_{\text {mag }}$ & 7,500 & $\mathrm{~kg} / \mathrm{m}^{3}$ \\
$F_{s}$ & 800 & $\mathrm{~Hz}$ \\
$J_{r m s}$ & 15 & $\mathrm{~A} / \mathrm{mm}^{2}$ \\
$I_{r m s}$ & 34 & $\mathrm{~A}$ \\
$T_{p h}$ & 55 & \\
$I_{d s c}$ & 69 & $\mathrm{~A}$ \\
$L_{s}$ & 0.34 & $\mathrm{mH}$ \\
$k_{w}$ & 0.8 & \\
$B H_{m a g}$ & 210 & $\mathrm{~kJ} / \mathrm{m}^{3}$ \\
$B_{m t}$ & 1.6 & $\mathrm{~T}$ \\
$n_{r}$ & 12,000 & $\mathrm{RPM}$ \\
$P_{r}$ & 23 & $\mathrm{~kW}$ \\
$P F$ & 0.9 & \\
$C P P$ & 0.5 & \\
$\% \eta$ & $95.5 \%$ & \\
\hline
\end{tabular}

Table 4 Losses calculation results.

\begin{tabular}{lllll}
\hline Loss (W)/part & \multicolumn{2}{l}{ Eddy-current Hysteresis } \\
loss & loss & $\begin{array}{l}\text { Windage } \\
\text { loss }\end{array}$ & $\begin{array}{l}\text { Total } \\
(\mathrm{W})\end{array}$ \\
\hline Winding & 550 & - & - & 550 \\
Stator & 110 & 94 & - & 200 \\
back-iron & & 160 & - & 610 \\
Stator tooth & 450 & - & - & 160 \\
PMs & 160 & 6 & - & 10 \\
Shaft & 4 & - & 2 & 2 \\
Rotor-surface & - & - & 0.1 & 0.1 \\
Rotor-ends & - & - & - & 1 \\
Sleeve & 1 & 260 & 2.1 & $1,533.1$ \\
\hline Total (W) & 1,275 & & & \\
\hline
\end{tabular}

\section{Acknowledgment}

The authors gratefully acknowledge the contribution of Dr. D. Staton from Motor design Ltd, UK.

\section{References}

[1] Cao, W., Mecrow, B. C., Atkinson, G. J., Bennett, J. W., and Atkinson, D. J. 2012. "Overview of Electric Motor Technologies Used for More Electric Aircraft (MEA)." IEEE Trans. on Industrial Electronics 59 (9): 3226-7.

[2] Alastair, F. 2008. Practical Application of CAD in a High Power Density Motor for a Very Short Duty Aerospace Actuator. London: Electro-Kinetic Designs Ltd., UK.

[3] Zhang, B., Qu, R., Fan, X., and Wang, J. 2015. "Thermal and Mechanical Optimization of Water Jacket of Permanent Magnet Synchronous Machines for EV Application." Presented at the IEMDC, Coeur d'Alene, Idaho, USA.

[4] Asef, P., and Perpina, R. B. 2016. "Losses Calculation of an Aerospace Retraction Wheel Motor with Regarding to Electromagnetic-Field Analysis Investigation." Journal of Energy and Power Engineering 10 (3): 183-90. doi: 10.17265/1934-8975/2016.03.006, ISSN 1934-8975.

[5] Holman, J. P. 2010. Heat Transfer. New York: Mc Graw Hill, 1-18, 265, 313, 362. ISBN: 978-0-07-352936-3.

[6] David, A. S., and Cavagnino, A. 2008. "Convection Heat Transfer and Flow Calculations Suitable for Electric Machines Thermal Models." IEEE Trans. on Industrial Electronics 55 (10): 3509-13.

[7] Boglietti, A., Cavagnino, A., and Staton, D. 2008. "Determination of Critical Parameters in Electrical Machine Thermal Models." IEEE Trans. on Industrial Applications $\quad 44 \quad$ (4): $1150-1$, doi:10.1109/TMAG.2015.2445940.

[8] Jung, J. W., Lee, B. H., Kim, D. J., Hong, J. P., Kim, J. Y., Jeon, S. M., and Song, D. H. 2012. "Mechanical Stress Reduction of Rotor Core of Interior Permanent Magnet Synchronous Motor.” IEEE Trans. on Magnetics 48 (2): 912-3. doi:10.1109/TMAG.2011.2172582. 